\title{
BLOOD GLUCOSE CONTROL AND COMPLIANCE OF DIABETIC CHILDREN
}

\section{FPR de VILLIERS, E CHESTER and KEC MEYERS}

\begin{abstract}
\section{Aim of Study}

Non-compliance is an important factor hindering good control in diabetics. The aim of this study was to identify areas of poor compliance with the diabetes management regimen in the children attending our clinic.
\end{abstract}

\section{Design}

A questionnaire was administered to 57 patients who attend the Paediatric Diabetes Clinic. It was designed to elicit socio-demographic data and information about the diabetic regimen. Prior to the administration of the questionnaire, patients were classified as being well, satisfactorily or poorly controlled, based on their average glycosylated Haemoglobin results over the past year.

\section{Results}

All the patients used home blood glucose monitoring (HBGM) - 79\% of the poorly controlled children tested twice daily or less whereas $53 \%$ of the well controlled children tested three times or more daily. The timing of injections was frequently incorrect. $42 \%$ of all patients had been admitted to hospital after diagnosis and more than $60 \%$ of them never tested their blood glucose in relation to exercise.

The patients' knowledge about their disease was generally good. The mean age of the poorly controlled group was almost 19 months older than that of the well controlled group. Poorly controlled children had also had diabetes for longer and they lived significantly further from the hospital.

A higher percentage of poorly controlled patients were in charge of their own treatment while those in the well controlled group were less reliant on doctors for insulin dose adjustments.

\section{INTRODUCTION}

Non-compliance has been identified (Belmonte, Schiffrin, Dufresne, Suissa, Goldman \& Polychronakas, 1988) as the most important factor hindering the diabetic patient's achievement of good glycaemic control. The complexity of the treatment regimen, which requires attention to many factors other than simple drug administration, "is one of the main factors associated with poor compliance". (Belmonte et al, 1988)

The fact is that diabetes places numerous behaviourial demands on the patient. (Johnson, 1992) Fulfilling all these tasks properly and at the right time is not easy. An alternative term for compliance is adherence, (Johnson,1992) and perhaps the latter is to be preferred when dealing with such a complex phenomenon as the management of diabetes, as "compliance" connotes obedience to medical staff, while "adherence" implies a more positive and active role on the part of the patient.

The aim of this study was to identify areas of poor compliance with the diabetes management regimen in the children attending our clinic. This would enable us to improve patient care and education, which may reduce the risk of long-term complications of Insulin-dependent Diabetes Mellitus.

\section{METHODS}

The study was aimed at children attending the Paediatric Diabetic Clinic of Johannesburg Hospital. All age groups were included. Patients attending the Clinic between February and April 1991 were studied. A questionnaire incorporating various aspects of the diabetic regimen was designed. Apart from sociodemographic questions, the following were established: the period of time the patient had had diabetes, the insulin therapy, complications of diabetes, home blood glucose monitoring, record keeping, status of knowledge about diabetics and aspects of nutrition and exercise. Questionnaires were handed to patients or parents at their clinic visit. Before the clinic visit the patient's average $\mathrm{HbA}_{1 \mathrm{C}}$ over the past year was calculated and recorded on the questionnaire which was anonymous. The patients or parents filled in the questionnaire on the clinic day and placed it in a box provided for the purpose. Confidentiality was maintained by storing the questionnaires together and analyzing them after all had been collected. No identifying marks were made on the questionnaires. A total of 57 questionnaires were returned. No changes in daily diabetic management were introduced at the time of the questionnaire.

Permission to conduct research in the Johannesburg Hospital was obtained from the Superintendent. Permission was also obtained from the clinic. The study was approved by the Committee for Research on Human Subjects of the University of the Witwatersrand. Data analyses were done with the N W Statpak, using appropriate t-tests and $\mathrm{Chi}^{2}$-tests.

\section{RESULTS}

Patients were grouped according to their average glycosylated Haemoglobin results as follows:

\section{Group 1 HbAIC less then 9,89\%} - good control

Group $2 \mathrm{HbA}_{\mathrm{IC}}$ between 9,9 and $12 \%$ - satisfactory control

Group 3 HbA IC more than $12,1 \%$ - poor control (Frankel,1987)

Table 1 indicates selected demographic data, including the age, sex, race and socio-economic status of the patients.

More girls than boys are poorly controlled but this does not reach statistical significance. Most of the patients in the study are white. This reflects the population that attends the Johannesburg Hospital Diabetes Clinic for two reasons:

1.The Johannesburg Hospital was, until about 5 years prior to the study, a segregated hospital.

2.Type I Diabetes Mellitus appears to be more common in whites than in blacks in Southern Africa.(Shires, Maier, Lustig, Barnett, Joffe, Seftel, 1983)

Table 2 reflects the distance the patients live from the hospital. The hypothesis was that poorly controlled patients may live further away from hospital than well controlled patients. There is indeed such a trend. Group 3 live significantly further away from the hospital $(t=$ $\left.2,061 \_1,684 ; \mathrm{p} 0,05\right)$. Most patients use private transport.

The mean duration of the disease in Groups 1 $(3,66 \pm 3,77$ years) and $2(3,48 \pm 3,44$ years $)$ is similar. When comparing Groups 1 and 3 (mean $4,7 \pm S D$ 3,68) the difference almost reaches statistical significance $(t=-1,604-1,684 ; 0,10$ p 0,05); there is a trend towards patients in the "poor control" group having had diabetes for a longer period of time.

Control of treatment is reflected in Table 3. Parents are in charge of the treatment in half to two-thirds of all patients. There is a trend 
TABLE 1: DEMOGRAPHIC DATA

\begin{tabular}{|c|c|c|c|}
\hline GROUP 1 & GROUP 2 & GROUP 3 & COMBINED \\
\hline $10 \pm 4,6$ & $10 \pm 3,6$ & $11,64 \pm 3,6$ & \\
\hline $11(65 \%)$ & $7(47 \%)$ & $10(40 \%)$ & $28(49,1 \%)$ \\
\hline $6(35 \%)$ & $8(53 \%)$ & $15(60 \%)$ & $29(50,9 \%)$ \\
\hline 14 & 13 & 22 & $49(86 \%)$ \\
\hline 1 & 0 & 1 & $2(3,5 \%)$ \\
\hline 1 & 0 & 0 & $1(1,7 \%)$ \\
\hline 1 & 2 & 2 & $5(8,8 \%)$ \\
\hline 0 & 5 & 3 & $8(14 \%)$ \\
\hline 5 & 3 & 9 & $17(30 \%)$ \\
\hline 8 & 6 & 10 & $24(42 \%)$ \\
\hline 0 & 0 & 0 & $0(0 \%)$ \\
\hline 0 & 1 & 3 & $4(7 \%)$ \\
\hline 4 & 0 & 0 & $4(7 \%)$ \\
\hline 13 & 14 & 20 & $47(82 \%)$ \\
\hline 3 & 1 & 4 & $8(14 \%)$ \\
\hline 1 & 0 & 1 & $2(4 \%)$ \\
\hline 17 & 15 & 25 & 57 \\
\hline
\end{tabular}

TABLE 2: TRANSPORT

GROUP 1

GROUP 2

GROUP 3

COMBINED

Distance from

\begin{tabular}{lcrrr} 
Hospital $(\mathrm{km} \pm \mathrm{SD})$ & $28,7 \pm 27,0$ & $38,4 \pm 21,8$ & $49,8 \pm 35,8$ & \\
Mode of Transport & & & & \\
Private & 11 & 14 & 23 & $84,25 \%$ \\
Public & 3 & 1 & 1 & $8,75 \%$ \\
Both & 3 & 0 & 1 & $7 \%$ \\
Comparison of groups 1 and 3: $\mathrm{t}=-2,061 . \mathrm{p} \mathrm{0,05}$ & & & \\
\hline
\end{tabular}

Table 3: CONTROL OVER TREATMENT (in percentages)

$\begin{array}{llll}\text { GROUP } 1 & \text { GROUP } 2 & \text { GROUP } 3 & \text { COMBINED }\end{array}$

In charge of treatment

\begin{tabular}{lrrrr} 
Patient & $18 \%$ & $20 \%$ & $28 \%$ & \\
Parent & $53 \%$ & $67 \%$ & $56 \%$ & \\
Both & $29 \%$ & $13 \%$ & $16 \%$ & \\
Gives Injections & & & & $46 \%$ \\
Patient & $41 \%$ & $47 \%$ & $48 \%$ & $42 \%$ \\
Parent & $47 \%$ & $47 \%$ & $36 \%$ & $7 \%$ \\
Both & $12 \%$ & $6 \%$ & $4 \%$ & $5 \%$ \\
(Missing information) & $0 \%$ & $0 \%$ & $12 \%$ & \\
Frequency of Clinic Attendance & $82 \%$ & $60 \%$ & $64 \%$ & \\
3-monthly & $6 \%$ & $27 \%$ & $24 \%$ & $91 \%$ \\
Monthly & & & & \\
Keoping appointments & $16(94 \%)$ & $15(100 \%)$ & $21(84 \%)$ & $0 \%$ \\
Always & $1(6 \%)$ & 0 & $4(16 \%)$ & 0 \\
Usually & 0 & 0 & & \\
Intrequently & & & & \\
\hline
\end{tabular}

towards more patients in Group 3 being in charge of their treatment, but this is not statistically significant. In all groups, patients and parents take approximately equal responsibility for giving injections. Clinic attendance is more often monthly in Groups 2 and 3 than in Group 1 and $16 \%$ of Group 3 patients confessed to not always keeping their appointments at the clinics, but neither of these trends is significant.

There is a trend towards increasing numbers of hospital admissions, from a third of children in Group 1, to about half the children in Group 3 having been re-admitted some time after their time of diagnosis (Table 4). Twenty per cent of Group 3 patients were admitted more than once. Hyperglycaemia was more frequently the reason for admission in Groups 2 and 3, than in Group 1.

Table 5 reflects the patients' blood glucose monitoring practices at home (HBGM). Most patients (88\%) monitor blood only, and most of them (82\%) own an electronic blood glucose monitoring device. No patient relies solely on the monitoring of urine. The frequency of HBGM varies considerably between the groups. About half of Group 1 patients monitor more than 3 times a day, while only $21 \%$ of Group 3 patients monitor that often. This difference is statistically significant. A small proportion of patients check their blood glucose level in relation to exercise: $12 \%$ test every day before, and $10 \%$ test every day after exercise. About two-thirds of patients never monitor their blood glucose either before $(63 \%)$ or after exercise (67\%). There was no difference between the groups.

Insulin therapy is noted in Table 6. Most patients are on a twice-a-day insulin regimen. The basal-bolus regimen is used by $17 \%$ of the respondents; most of these are in Group 3. All patients claim never (or hardly ever) to forget their insulin injections, and more than half take responsibility for changing the insulin dose, rather than relying exclusively on the doctor. None of the intergroup differences is statistically significant.

Knowledge of their disease was tested and results are given in Table 7 . The majority of patients have an adequate knowledge of their disease as tested in this questionnaire. Ninety-three per cent know the symptoms and treatment of hyperglycaemia, as well as the site of production of insulin; $86 \%$ can name the target blood sugar levels correctly; $72 \%$ know the function of insulin and $68 \%$ that of glucagon. The patients' opinions about their education are very positive (Table 7). The majority feel that their education is adequate, that they have access to further education and that the staff is approachable.

\section{DISCUSSION}

The questionnaires were handed out over a period of seven weeks; the parent or patient then filled them in. Not all patients attended the clinic 
Table 4: RE-ADMISSIONS

\section{$\begin{array}{llll}\text { GROUP } 1 & \text { GROUP } 2 & \text { GROUP } 3 & \text { COMBINED }\end{array}$}

Ever admitted

after diagnosis

Yes

$6(35 \%)$

$11(65 \%)$

$2(12 \%)$

More than once

Reasons for admission*

Hypoglycaemia

Hyperglycaemia

Infection

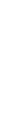

$$
6(40 \%)
$$

2

4

0

Know what ketoacidosis is

"No"

$29 \%$

$27 \%$

$32 \%$

$24(42,1 \%)$

$33(57,9 \%)$

$8(14 \%)$

$41.7 \%$

$66,7 \%$

$4.2 \%$

$29 \%$

Refers to number of patients, not number of admissions.
For these reasons, non-compliant patients may be expected more frequently in these age groups. The fact that the mean age in Group 3 was 1 year 7-3/4 months older than Group 1, confirms Daneman et al's. opinion that compliance is perhaps poorest in adolescence. (Daneman, Siminerio, Transue, Betchart, Drash \& Becker, 1985)

The trend for patients in the poor control group to have had diabetes longer than those in the good control group almost reaches statistical significance. This could be due to some patients who are still in partial remission being included in the good control group, or may be due to waning patient enthusiasm. The fact that more of the Group 3 patients are adolescents also plays a role in this respect.

Patients in the poor control group live significantly further from the hospital than those in the good control group. This factor has been found to be important in the compliance of renal transplantation patients (Meichenbaum, 1987; Didlake, Dreyfus, Kerman, Van Buren, Kahan, 1988). It may be that, apart from the cost and travelling time involved, a greater distance from the hospital creates a feeling of being removed from the clinic and, therefore, distanced from both the control of the disease exerted by the clinic and the support derived from clinic staff.

Whether the patient takes direct responsibility for his treatment may depend on whether he believes that his disease and its management is controlled by forces outside himself (external locus of control) and may occur independently of his own actions, or the converse. (Frankel, 1987) Some studies state that a relationship exists between poor control and an external locus of control(Alogua, 1980; Hamburg \& Inoff 1982), although a study in Johannesburg could not confirm this relationship. (Frankel, 1987)

In our study, more of the poorly controlled patients are in charge of their treatment without parental supervision (this difference does not reach statistical significance). This may reflect the fact that this group is older and has had the disease for a longer period and, therefore, does not need the supervision, but may also reflect lack of interest by the parents or conflicts which may have led to the patients excluding their parents from decisions.

On the other hand, $42 \%$ of Group 3 patients rely on the doctor for insulin dose adjustments, compared with $35 \%$ of Group 1 patients, suggesting that patients in the poor control group are more reliant on doctors, but less reliant on their parents than patients with good control. Further study is clearly necessary to explain this phenomenon.

A larger proportion of poorly controlled patients attend the clinic monthly, rather than three-monthly. This reflects the clinic's policy: newly diagnosed patients attend monthly until they are confident in the management of diabetes, as do those patients experiencing 
problems and poorly controlled patients, while stable patients attend three-monthly.

Most patients claim to keep all their appointments, although fewer in the poor control group do. In a survey of our clinic records over a 6-month period, it was noted that $24 \%$ (21 out of 87) of appointments were not kept (Sr D D Green, professional diabetes nurse, personal communication). The patients' impression of their regularity in keeping appointments is, therefore, probably an overestimate.

Home blood glucose monitoring has become one of the mainstays of management of Type $I$ diabetes, (Belmonte et al 1988) even though, not very long ago, it had to be proven that this was possible in children. (Geffner, Kaplan, Lippe \& Scott, 1983). All the patients in the study use HBGM, and $12 \%$ combine it with urine testing. Most (82\%) own an electronic blood glucose monitoring device. This is in accordance with the socio-economic status of our clinic population.

Significantly more of the children in Group 3 test their blood glucose level twice a day or less often, compared with those in Group 1 (79\% vs. $47 \%$ ). It is interesting to note that this is in contradiction to the clinic's policy, which is that a newly diagnosed, ill, or poorly controlled diabetic should test more often than twice a day, and should stagger the timing of the tests, but that well controlled diabetics need test only twice a day. While it is not surprising that the poorly controlled patients do not test frequently enough, since they have been defined as not adhering to their management, it is noteworthy that more than half of the well-controlled patients, in contradiction to clinic policy, test frequently. It has been stated that testing twice a day is necessarily associated with poorer control than testing four times a day (Schiffrin $\&$ Belmonte, 1982) - an association that has also been shown here.

Whether this is true when testing twice a day, but in staggered fashion over a week, is not clear. However, the clinic may have to modify its recommendations and, indeed, recommend more frequent testing for all patients except, perhaps, those who are enjoying a remission.

A very small proportion of our patients test regularly before or after exercise, and a staggering two-thirds never test in relation to exercise. It is the clinic's policy that patients ought to test in relation to exercise whenever a change occurs, e.g. a new exercise programme is embarked on (this will include the commencement of a new season in a sport the diabetic has taken part in before); any part of the diabetic management regimen is changed (e.g. insulin dose, insulin distribution or change in diet); or when symptoms occur during or after exercise sessions. Patients are also expected to test occasionally (frequency not defined) when the exercise and diabetic management regimens are stable. It is likely that the patients are not sufficiently aware of this policy. However, many of our patients perceive it to be socially unacceptable to do blood tests near the sport
TABLE 6: INSULIN THERAPY

$\begin{array}{llll}\text { GROUP } 1 & \text { GROUP } 2 & \text { GROUP } 3 & \text { COMBINED }\end{array}$

Frequency of dose

Morning and evening

12

11

19

$78 \%$

Before meals and

at bedtime

1

Once a day

2

Timing of dose: Same time?

Yes

No

Usually

11

0

Forgetting injection

Very rarely/never

3

$17 \%$

$5 \%$

1

$58 \%$

$7 \%$

$35 \%$

Adjustment of Insulin dose

\begin{tabular}{|ccccc|} 
Patient & 11 & 7 & 14 & $58 \%$ \\
Doctor & 6 & 7 & 10 & $42 \%$ \\
\hline
\end{tabular}

\begin{tabular}{|lrrr|}
\hline \multicolumn{4}{c}{ TABLE 7: KNOWLEDGE AND EDUCATION } \\
\cline { 2 - 4 } & \multicolumn{3}{c|}{ ANSWER } \\
\cline { 2 - 4 } & Correct & Wrong & No answer \\
Function of insulin & $72 \%$ & $21 \%$ & $7 \%$ \\
Site of production of insulin & $93 \%$ & $2 \%$ & $5 \%$ \\
What is glucagon used for? & $68 \%$ & $9 \%$ & $23 \%$ \\
Symptoms and treatment of hypoglycaemia & $93 \%$ & $0,5 \%$ & $6,5 \%$ \\
Target blood sugar level & $86 \%$ & $0 \%$ & $14 \%$ \\
& & & \\
& Yes & No & Mostly \\
\cline { 2 - 4 } Are staff approachable? & $96 \%$ & $0 \%$ & $4 \%$ \\
Adequate diabetes education & $75 \%$ & $3,5 \%$ & $21,5 \%$ \\
Access to further information & $77 \%$ & $23 \%$ & $0 \%$ \\
\hline
\end{tabular}

fields or in changing rooms. The clinic will need to stress this aspect.

The percentage of patients on a basal-bolus regimen increases from Group 1, through Group 2 to Group 3. The basal-bolus regimen is not a guarantee of improved glycaemic control, but we did not expect that the basal-bolus regimen would be associated with worse control than a twice-a-day mixed insulin regimen. We therefore ascribe this finding to the older age of the patients in Group 3.

All the patients claim to give all their injections, although about $40 \%$ do not give these at the same time every day. If the $17 \%$ of the sample on the basal-bolus regimen who are allowed to vary the time of their meals and injections are excluded one-fifth of these children still do not adhere to the correct timing of their injections.

Thirty per cent of the children do not know what glucagon is used for, nor what the function of insulin is.

While the answer to the latter question may not be very important in practical terms, the answer to the former question is, and may influence how these patients and their parents approach an attack of hypoglycaemia.

In general, however, the knowledge of these patients is good. They also feel that the staff is approachable, and that they have adequate access to further information.

\section{CONCLUSION}

Distance from the hospital contributed to poor control, as did duration of diabetes, frequency of breaking appointments and infrequent self testing of blood glucose.

In all groups, an unacceptably high percentage of patients needed readmission for diabetes-related problems, and testing in relation to exercise was unsatisfactory. Timing of injections was also incorrect in too many cases. These issues will be addressed in the clinic's internal diabetes education programme.

The patients had sufficient knowledge of their disease and were positive about the contribution of the clinic. Their behaviour did, however, not always match up to their knowledge and attitude. 


\section{ACKNOWLEDGEMENTS}

Thanks are due to Sr D D Green of the Paediatric Diabetes Service; the patients and parents who willingly cooperated; the Postgraduate Paediatric Nursing students, viz. Shirley de Vos, Sheila Masuku, Penny Mmofsoa, Faith Msomi and Gill Treadway who participated in data collection; Ms Cindy Lerwill, the tutor of that course and instigator of this research project, and Ms Cathy Burton for editorial assistance and close scrutiny of the tables.

\section{REFERENCES}

Alogua M. (1980): Perception of severity of disease and health locus of control in compliant and non-compliant diabetic patients. Diabetes Care; 3 : 533-534.

Belmonte MM, Schiffrin A, Dufresne J, Suissa A, Goldman H, \& Polychronakas C. (1988). Impact of S.M.B.G. on control of Diabetes as measured by $\mathrm{HbA}_{1}$-three year survey of a Juvenile IDDM Clinic. Diabetes Care; 11 (6): 484-488.

Daneman D, Simenerio L, Transue D, Betschart J, Drash A, \& Becker D. (1985): The role of self-monitoring of blood glucose in the routine management of children with Insulin-dependent Diabetes Mellitus. Diabetes Care; $8: 14$
De Villiers FPR. (1992): Diabetes Mellins in preschool children - an orphan disease? South African Medical Joumal; 81: 491-492.

Didlake RH, Dreyfus K, Kerman RH, van Buren CT, \& Kahan BD (1985): Patient non-compliance: A major cause of late graft failure in Cyclosporin-treated renal transplants. Transplantation Proceedings; 20(3): 63-69

Frankel RM (1987): Diabetic Control in Adolescence. Unpublished D Litr et Phil thesis: RAU: Johannesburg.

Geffner ME, Kaplan SA, Lippe BM, \& Scott MI (1983): Self-monitoring of blood glucose levels and intensified insulin therapy: acceptability and efficacy in childhood diabetes. Journal of the American Medical Association; 249: 2913-16.

Hamburg BA, \& Inoff GE (1982): Relationship between behavioural factors and diabetic control in children and adolescents: A camp study. Psychomatic Medicine; 44: 321-339

Johnson SB. (1992): Methodological Isues in Diabetes Research: Measuring Adherence. Diabetes Care; 15:1658-1667.

Meichenbaum D. (1987): Facilitating Treatment Adherence - a practitioner's guidebook. New York: Plenum Press.

Schiffrin A, \& Belmonte M (1982): Multiple daily self-glucose monitoring: its essential role in long term glucose control in insulin-dependent diabetic patients treated with pump and multiple subcutaneous injections. Diabetes Care; 5:479-84.

Shires R, Maier G, Lustig A, Barnett P, Joffe BI, Seftel HC. (1983): HLA antigens in white and black South African diabetics. South African Medical Journal; 64:1087-1089.

Stearns S. (1959): Self-destructive behaviour in young patients with diabetes mellitus. Diabetes; 8:379-382.

Tattersall RB. (1981): Psychiatric Aspect of Diabetes - a Physicians's view. British Journal of Psychiatry; 139L:485-493

François P R de Villiers,
MBChB, PhD, MMed
Department of Paediatrics \& Child Health
MEDUNSA
Emma Chester,
RN, RM, R Paed N, Cert Neonat N
Kevin E C Meyers,
MBChB, FCP, DTM \& H
Department of Paediatrics and Child
Health
Johannesburg Hospital and the
University of Witwatersrand

